\title{
6. Buddhist Surrealists in Bengal
}

Per Kværne

\section{Abstract}

Towards the end of the first millennium CE, Buddhism in Bengal was dominated by the Tantric movement, characterized by an external/physical as well as internal/meditational yoga, believed to lead to spiritual enlightenment and liberation from the round of birth and death. This technique and its underlying philosophy were expressed in the Caryaggiti, a collection of short songs in Old Bengali composed by a category of poets and practitioners of yoga, some of whom apparently had a peripatetic lifestyle. One of the peculiarities of Old Bengali is the presence of a large number of homonyms, permitting play on ambiguous images. This, it is argued in the first part of the chapter, is the key to understanding many songs that are seemingly meaningless or nonsensical, or that could be superficially taken to be simply descriptions of everyday life in the countryside of Bengal. By means of their very form, the songs convey the idea of the identity of the secular and the spiritual, of time and eternity. The second part of the chapter makes a leap in time, space, and culture, by suggesting a resonance for the Caryāgiti in the Surrealist Movement of Western art.

Having milked the tortoise the basket cannot hold -

How to cite this book chapter:

Kværne, P. 202 I. Buddhist Surrealists in Bengal. In: Larsson, S. and af Edholm, K. (eds.) Songs on the Road: Wandering Religious Poets in India, Tibet, and Japan. Pp. II3-I26. Stockholm: Stockholm University Press. DOI: https://doi.org/Io.I6993/bbi.f. License: CC-BY 4.o. 
the alligator devours the tamarind of the tree.

The courtyard is in the house -

listen, o dancing-girl!

The rag was carried off by the thief at midnight.

The mother-in-law fell asleep, the daughter-in-law stays awake.

The rag was carried off by the thief -

where shall one go to search for it?

By day the crow frightens the daughter-in-law by night she goes to meet her lover.

The noble Kukkuri sings of such conduct among millions, it has entered but a single heart. ${ }^{279}$

This enigmatic song is one of the approximately fifty short poems that constitute a collection known as the Caryāgiti, 'Songs of (Yogic) Practice'. This collection of poems is generally regarded as one of the very last Buddhist texts to have been composed and committed to writing in India, perhaps in the $\mathrm{I} 2^{\text {th }}$ century. They are written in a language usually referred to as Old Bengali, and constitute the earliest literary work preserved in any modern Indo-Aryan language, or, put more simply, in any major language in North India. ${ }^{280}$

It is not so easy to understand what the poet, Kukkuri, is trying to say, so let us start by reading one more song, before we attempt to understand them.

The boat of Compassion is filled with gold silver has been left on the shore.

Steer on, o Kamali, towards the sky!

Birth is no more - how can it come back?

The peg is pulled up, the rope cast off ask your Guru, o Kamali, and steer on!

Ascending the stern, he gazes in all directions.

There is no oar -

how can you row across the river?

${ }^{279}$ Kværne I986 (I977). The song quoted is number 2 according to the standard sequence of the songs.

280 Kværne I986 (I977). 
Ascending the stern,

he presses the oar to the right and the left thus he finds great happiness on the way. ${ }^{28 \mathrm{I}}$

We are in Bengal, the land of languid rivers, where boats have always been the most important means of transport. But how does this glimpse of timeless daily life disclose a spiritual dimension? Is there a secret message hidden behind the image?

We might begin by noting that most of the poems in the Caryāgìti use images from nature and from rural life in Bengal. Were the authors of the songs "wandering poets"? Certainly, some of them were itinerant, especially Kaṇha (or Kṛṣna), the most prolific of the poets, to whom no less than twelve songs are attributed. He calls himself a kāpälika, a homeless yogin who frequents the charnel-grounds and drinks from a human skull (Sanskrit kapāla). Kaṇha's songs describe the life of such yogins, as well as their female partners, yoginis. Together they challenge the conventions of society and roam about naked, their bodies smeared with ashes from fires where corpses are cremated. They wear ornaments carved from human bones and use sexual techniques to achieve spiritual enlightenment - or at least, so it is claimed in the songs.

However, a number of the poets may be regarded as "wanderers" in a wider sense, for while some - potters and weavers - live in villages, the way of life of others - hunters and arrowmakers - define them as "outsiders". In an existential sense, at least, they are wanderers, being despised and rejected. Gundari was a hunter of birds. Śabara belonged to the jungle-dwelling tribe of Sabar or Saora, which still lives in the forests of Central India and West Bengal. ${ }^{282}$ Bhade was a painter, Tantri a weaver, Saraha an arrow-maker, and Kạ̣ha was, as mentioned, an itinerant yogin. All of these poet-yogins, however, whether villagers or itinerant, crowd together on the lowest rungs of the social ladder, on the very margins of society, in the company of prostitutes and yoginīs. They live on the periphery of society, in a kind of social no-man's land.

${ }^{281}$ Kværne I986 (I977), song 8. The boat is propelled by stern sculling.

282 Cf. Mahaswati Devi 2002. 
This is the kind of individuals that in the songs declare themselves to be their authors, each song normally ending with a line where the author discloses his name. In this way, the songs are attributed to a particular category of yogins, known from other sources and belonging to the late Buddhist tradition of India. They are usually called siddha, a Sanskrit word literally meaning 'accomplished', but which might be translated in this context as 'spiritual master', one whose accomplishment is to have obtained release from the round of birth and death in the wheel of transmigration.

It is worth noting that the poetic and religious tradition of the siddhas continued to exert an influence even after Buddhism practically disappeared from Bengal at the same time as the Muslim conquest in the $\mathrm{I} 3^{\text {th }}$ century. Thus, the erotic terminology in the cary $\bar{a}$-songs has probably left an imprint on the later Hindu poetry in Bengal with its emphasis on the love between the deity in the form of Kṛ̣na and the soul, envisaged as Rādhā, Kṛṣna's passionately enamoured mistress. ${ }^{283}$ The most important and direct heritage of the Caryāgiti, however, is beyond doubt to be found in the songs of the Bauls of Bengal, itinerant devotees of "the Divine Spark" manifesting itself in the hidden depths of the soul, a divinity they worship through songs full of longing and passion and images reminiscent of those found in the Caryāgìti. The Bauls, still a living tradition, in turn inspired Rabindranath Tagore, and through him, modern Bengali culture and literature as a whole. ${ }^{284}$ For this reason there is still a considerable interest in the Caryāgit $t i$ in literary and academic circles in West Bengal as well as in Bangla Desh.

Ever since the songs were published for the first time in I9I 6,285 it has been generally taken for granted that the concrete, everyday images they contain in such abundance have an immediately understandable significance as well as a deeper, hidden meaning. That this is the case, is evident not only from the very form of many of the songs, where philosophical concepts are linked with objects from daily life such as "the boat of compassion", and so on, but more particularly by the fact that the songs, in the manuscript

\footnotetext{
${ }^{283}$ Dimock I989.

284 Openshaw 2002.

285 Shastri (ed.) 2006.
} 
in which they have been preserved, are inserted in a learned commentary where each song is interpreted and commented on.

This commentarial text is a late example of the Buddhist scholarly tradition in India - it is composed in Sanskrit, the language of learning, and abounds in quotations from other Sanskrit texts. Composed by an otherwise unknown scholar by the name of Munidatta, it is based on a unified, coherent interpretation of the songs in terms of a yogic system. According to Munidatta, therefore, the concrete images are to be understood as allusions to the body's energy-centres, the so-called cakras, 'wheels', that are activated by means of specific meditational and physiological techniques. Among these techniques are breath-control and certain ways of manipulating sexual energy, represented by the male sexual fluid. By means of these techniques the siddha obtains a state of boundless bliss, in which all concepts of contrast or duality, such as "subject" and "object", "then" and "now", "I" and "other" are transcended and eliminated.

Previous translators and interpreters have generally read the songs in terms of Munidatta's commentary. I, too, used the commentary in my doctoral dissertation, published in $1977 .{ }^{286}$ I shall return to my interpretation below. At the same time, the majority of those who have published translations of the songs have been fascinated by the concrete images, and understood them as realistic and factual descriptions of the nature and culture of Bengal a thousand years ago. As an example of the emphasis placed on these concrete images, I shall quote from a study of the songs by Hasna Jasinuddin Moudud, a prominent figure on the cultural scene in Bangla Desh, published in I992.287 She writes perceptively as follows about the imagery of the songs:

They give us a vivid account of the life and occupations of the common people, their work, events of birth, marriage and death, religious activities, dress and ornaments, food and utensils, and music and musical instruments. There is also a beautiful description of the riverine and green eastern part of

${ }^{286}$ Kværne I977. See first note.

${ }_{287}$ Moudud I992. For Moudud's translation, see also: http://vajrayana .faithweb.com/rich_text_3.html 
Bengal which is Bangla Desh today. The poems describe rivers, canals, ponds, muddy shores, various types of boats and their different parts, ferrying and rowing; all these were used... as spiritual symbols. ${ }^{288}$

She also writes:

From the Caryas one can get a vivid account of the life and professions of the common people. Rice was the staple food. Bulls were used for cultivation and cows were kept for milk. Wine making and drinking was common to men and women. Playing chess is mentioned in the Caryas. The use of gold and silver were common. Dancing and singing were considered natural activities. Hunting, weaving and ferrying represented different occupations. ${ }^{289}$

One naturally wonders whether there is a set pattern or system according to which images inspired by the mundane, visible world would consistently point to yoga-techniques and states of meditation related to the path of the siddhas towards ultimate enlightenment and release from birth and death. Scholars who have discussed this question have taken such corresponding meanings for granted, and with regard to certain key images this is no doubt true. Thus, the image of the yogini certainly represents the absolute freedom of spiritual enlightenment, for the central psychic energy-channel which follows the yogin's spine leads to the cakra of concentrated psychic power, located at the top of the head, the locus of the experience of absolute, liberating bliss. However, the central psychic channel can also be represented, according to Munidatta, by various women, all mentioned in the songs: a woman of the śabara-people, living in the jungle; or a dombi a woman of the despised outcaste dom-people; or the spouse of the unclean and casteless candala, whose task it was (and still is) to handle the cremation of corpses, the most potent source of ritual pollution; or a sundinī, the young woman who produces and serves alcohol, another despised and unclean activity. All these women come from the margins of society, yet all can represent the state of ultimate release from birth and death.

${ }^{288}$ Moudud I992:I.

289 Moudud I992:4I. 
However, the message of the songs - and of Munidatta's commentary - is more complex than these images might suggest. There is a duality, an absolute contrast of meaning, in many of the images. One and the same image can represent concepts pointing to release as well as pointing to the state of bondage in the material world of birth and death. The interpretation offered by Munidatta in his commentary of one and the same image sometimes points in one direction, sometimes in the opposite direction. For example, the image of the tree can symbolize the state of absolute freedom, but also the physical body. The river can indicate the central psychic energy-channel along the spine, but the entire system of psychic veins and arteries can also be an image of the illusory nature of existence in the world. The ocean can be the infinite luminosity of ultimate bliss in which all things and all concepts dissolve, but also the enslaving round of birth and death. In the same way, one could continue adding example to example. 290

It would be overhasty to draw the conclusion that the message of the siddhas as expressed in the songs is reproduced in the learned Sanskrit commentary of Munidatta, in which everything is interpreted according to a specific system of yoga. To me it is clear that there is an inherent ambiguity in many of the images found in the Caryāgitti. This ambiguity, I argue, is in many cases due to the fact that the phonetic development of different Sanskrit words results in a single phonetic form in the Caryaggiti $;^{291}$ in other words, what we find are homonymous words. This is by no means unusual in the early forms of North Indian languages, such as Hindi or Bengali, that have their origin in Sanskrit.

Just to give a couple of examples, I could cite the word $k \bar{a} u$ in the first song quoted, derived from Sanskrit kāka, 'crow'. However, it could just as well be derived from Sanskrit kāya, 'body', which is what Munidatta assumes. In the second song quoted, rūpa comes from Sanskrit rūpya, 'silver', but could also, as Munidatta suggests, be understood as derived from rūpa, 'form', in the sense of 'tangible form'. In the same song, sone could be derived from

${ }^{290}$ For a detailed survey of these images, see Kværne r977:passim.

29r Kværne I977:54-55. 
suvarna, 'gold', but just as well from śünya, 'emptiness'. So while I have translated literally: "The boat of Compassion is filled with gold - silver has been left on the shore", Munidatta's commentary would give an interpretation as follows: "The enlightened mind was filled by the absence of concepts - the material world was left behind". ${ }^{292}$ Many similar examples could be cited.

Besides homonymy, Munidatta makes use of artificial etymologies when interpreting words in the Caryāgitti. In this way he can ascribe to a word a profound or esoteric meaning for which there is no linguistic justification. Having said that, however, it should be added that some of these artificial etymologies were probably widely accepted in learned Buddhist and Hindu circles at the time of Munidatta, that is the $\mathrm{I}{ }^{\text {th }}$ or $\mathrm{I} 3^{\text {th }}$ centuries, and may well have corresponded to the understanding of the siddhas themselves. To take but one example, the word duli in the first song means 'tortoise'. This word is interpreted - in a totally artificial way - by splitting it into two components: $d u$ and $l i$. Du is, so Munidatta claims, derived from Sanskrit dvaya, 'two', understood as 'duality' (Munidatta: dvaya-äkâram), while li, he maintains, is the verbal stem $l \bar{l}$, 'to be dissolved, disappear'. Hence Munidatta interprets $d u l i$ as the psychic energy-centre at the top of the head, the locus where 'duality is dissolved', also referred to as 'the lotus of great bliss' - not quite the same as a 'tortoise'.

The kind of paradoxical, even nonsensical imagery found in the cary $\bar{a}$-songs is routinely called sandhyābhāss $\bar{a}$ in the commentary of Munidatta, and this term is found in other, similar late Indian Buddhist texts as well. However, while the term is often translated 'twilight-language', there is no consensus as to how it should be understood. ${ }^{293}$ Those who prefer the idea of 'twilight-language' have argued, to quote just one opinion, that "Sandhyābhāșā is a language of light and darkness; some passage can be understood, others cannot". ${ }^{294}$ Other translations are 'intentional speech', an interpretation which has been accepted by several scholars but which is flawed by the fact that it presupposes an emendation which is not attested in any of the manuscripts. 'Enigmatic speech'

\footnotetext{
292 Kværne I977:104.

293 Kværne I977:37.

294 Shastri I9I6.
} 
was proposed as early as I 852 by the great French Orientalist Eugène Burnouf, accepted by Shashibhushan Dasgupta in I946,295 and taken up again by the late David Snellgrove. ${ }^{296}$ These translations have one thing in common, namely that they assume that the siddhas did not wish to impart their teachings in direct, unambiguous terms. There are, however, a couple of further explanations as well, for example that the purpose was to provide "catchphrases to the common people", or even that "twilight-language" - the term I personally favour - was meant to be a joke. ${ }^{297}$

I shall not give any more examples, but proceed to my conclusion, which is my contribution to the interpretation of these songs, namely: in many of them, though not necessarily in all, it is the phonetic, formal aspect of the language of the poems - in other words, a language which is on the threshold between a late, Sanskrit-derived Middle Indian language and a modern North Indian language - which expresses, through its frequent use of homonyms and artificial etymologies, the concurrence and perfect coincidence of the relative and the absolute, the visible, material world and the invisible liberation from birth and death. It is this concurrence that is the very basis of the doctrine and practice of the siddhas. It is for this reason that the siddhas were generally strangers to the Buddhist monastic tradition. In fact, they made a point of placing themselves outside the norms and conventions of society at large, through their lifestyle as well as their philosophy. It is a paradox that it did not take long before their songs became, as we have seen, the subject of a learned commentary, and later on they were incorporated in the Tibetan collection of sacred scriptures, the doctrinal backbone of monastic, institutionalized Buddhism in Tibet.

\section{II}

It would be tempting - and certainly useful - to give a more coherent presentation of the religious system underlying the songs according to Munidatta's commentary. However, I will attempt a

\footnotetext{
295 Dasgupta I946.

296 Snellgrove I987:I6If.

297 Agehananda Bharati, quoted in Kværne I977:38.
} 
different approach. Keeping the ambiguity of the linguistic form of the songs in mind, I will make a leap through time and space, and without any pretence of historical or cultural continuity, land at an entirely different cultural phenomenon. I shall consider irresponsibly, perhaps - that a certain degree of common ground in terms of basic perception of the nature of existence may be discerned in two widely separated historical and cultural contexts.

In the early I920s, a movement appeared in Western Europe that became known as Surrealism. This movement was, in historical terms, a child of the Modernism that came to dominate the art scene early in the $20^{\text {th }}$ century, especially Cubism, represented by painters in Paris such as Pablo Picasso and Georges Braque, as well as the Italian Futurists, represented by members of the Italian avant-garde such as Giacomo Balla and Umberto Boccioni. Both these movements were characterized by their focus on dissolving the tangible form of objects: Cubism by dissolving objects and then re-assembling them in new and surprising ways, Futurism by exploring ways of depicting speed and dynamic motion by avoiding to give objects stability and solidity on the canvas. Taking this as a point of departure, the Surrealists took one more step ahead, not by dissolving form as such, but by completely dissolving the conventional meaning of objects, creating instead a world based on the "logic" of dreams and the sub-conscious, a world where there is neither up nor down, where the distinction between animals and humans is blurred, where what counts is the ambivalent, paradoxical, contradictory.

In this it is not difficult to see (or so I would maintain) a parallel, at least in imagery, to the carya $\bar{a}$-songs. As the great spokesman of the Surrealists, André Breton, said: "What is admirable about the fantastic is that there is no longer anything fantastic: there is only the real". ${ }^{298}$ The siddhas could not have put it more pointedly: it is that which is paradoxical that is "real", and reality itself is expressed by them in what they called 'the twilight-language' (sandhyābhāșa $)$, the speech of ambivalence, of twilight, midway between light and darkness, which points to "reality" precisely through its ambiguity. I would like to illustrate this approach to

${ }_{298}$ Spies \& Rewald (eds.) 2005:89. 
reality by looking at some of the paintings of the Surrealist painter Max Ernst (I 89 I-I 976). ${ }^{299}$ In the painting “Oedipus Rex" (I922), one observes three fingers of a hand emerging from a window to the left, holding a walnut and what appears to be a bow, while the nut is pierced by an arrow. To the right are two heads, one of a bird and another of a less easily identified creature. In the distant sky floats a tiny balloon. However, the proportion between the window and the hand is completely unbalanced. It is by no means clear what meaning, if any, the painting communicates. Still, it is difficult to avoid the impression that it does have a meaning, but if so, that meaning is precisely 'surrealistic' and cannot be uncovered by applying rational or empirical criteria. In fact, it is not certain that the meaning can be formulated in definable concepts or ideas at all.

Double meaning is often a basic theme in the art of Max Ernst, just as we have seen is the case in the cary $\bar{a}$-songs. In the painting "Castor et Pollution" (I923), two nearly identical male heads, staring intently in opposite directions, their shoulders turned back to back, emerge from a metal container on which the words "Castor et Pollution" are written. The container seems to be placed in sea with a distant bright blue, mountainous coast in the background and spanned by a yellow sky. Ernst offers an ironical play of words with reference to the mythological twins of Antiquity, Castor and Pollux, the patron divinities of seamen. Here the parallel to the Caryāgiti goes further, for the twins of Antiquity have - obviously - the same mother, but - paradoxically - different fathers: the father of Castor was Tyndareus, king of Sparta, while Pollux was the divine son of Zeus himself, who in the form of a swan seduced Leda. The human and the divine constitute a pair of twins, just as the limited and the unlimited are two sides of the same coin in the world of the cary $\bar{a}$-songs.

In "Birds, Fish-Snake; Scarecrow" (I92I) we once again see duality represented by an enigmatic single figure with two bird's heads, placed in an inchoate and seemingly meaningless world of dreams in which various objects - a jacket, a headless woman in a pink dress, a bag with a hand emerging and touching a snake,

299 See Spies \& Rewald (eds.) 2005. 
a cow that seems to be jumping over a fence, its head hidden by an outstretched hand - float about against a uniformly grey background. It is a topsy-turvy dream world of this kind that we find in one of the songs of the Caryāgiti:

My house is on the hill, no neighbour have I no rice in the pot, yet guests continually come! The frog chases the serpent can milk return to the udder?

The ox has given birth to a calf, but the cow is barren the basket is milked three times a day.

He who is wise, the very same is a fool he who a thief, the very same is a watchman. Ever and ever the jackal fights with the lion few are they who understand the song of the poet Dhendana! 300

One of Max Ernst's most famous (or, at the time, infamous) paintings is entitled "The Holy Virgin Chastises the Infant Jesus in the Presence of Three Witnesses: André Breton, Paul Élouard and the Artist" (I926). The Virgin Mary, complete with halo, is shown giving the child Jesus, lying face downwards on her lap, a spanking, while the heads of three representatives of the French avantgarde are seen watching impassively through a small opening in the wall behind Mary. That the picture created a scandal when it was first exhibited is not surprising, and Max Ernst certainly wanted to provoke conventional standards of propriety. In the same way it is not difficult to understand that in the familycentred Bengali society the siddha Kaṇha launched a provocation when he sings that,

Having killed his mother-in-law,

his aunt and sister-in-law -

having killed his mother

he has become an ascetic

who drinks wine from a skull! 30 r

300 Kværne I986 (I977), song 33.

3ог Kværne I986 (I977), song I I. 
Not surprisingly, in his commentary Munidatta offers a symbolic interpretation of this verse.

An equally confusing juxtaposition of 'reality' and 'illusion' is characteristic of the art of the Belgian Surrealist René Magritte (I 898-1967). ${ }^{302}$ In his painting "The Key to the Fields" (I936), we see a window on which a landscape has been painted; however, the window is broken and has visible cracks, and what appears behind is exactly the same landscape that was painted on the window. I suggest that what Magritte wanted to do, was to challenge the traditional attempt of Western art to reproduce nature, but I would also suggest that since we are trying to "make sense of" Surrealism in terms of the Caryāgiti, we could view the focus of the cary $\bar{a}$-songs on the identity between enlightenment and the world of birth and death as a parallel to Magritte's painting in which the coincidence of the painted window and the world outside turn out to be identical with the painting itself, the difference between them being an illusion.

Finally, in Magritte's painting "Portrait of Edward James" (1937), the English poet is standing with the back to us, facing a mirror in which, accordingly, we would expect to see his face. What we actually see, however, contradicts all logic and experience: we see an exact copy of the figure in front of the mirror. In other words, we are confronted by two realities: the everyday reality of a man with his back turned towards us and an intangible and paradoxical reality in the mirror, namely exactly the same figure with its back turned to us, not the reflexion that optical laws would lead us to expect. We are confronted with a portrait in which there is no face, which is in itself a paradox, but beyond that, we are confronted with two realities perceived at the same time, as in the Caryāgiti.

I am aware that my presentation of the cary $\bar{a}$-songs in the light of Surrealism may be somewhat on the periphery of conventional academic norms, just as Dhendana's hut is outside the village. However, I wanted to avoid looking at these songs essentially in terms of their historical context - what came before and what came after - and running the risk of being caught in a regressus

302 On Magritte, see Levy 2015. 
ad infinitum, a winding up of an endless historical thread. Instead I have attempted to make a leap in time and space and culture, in the hope of finding a resonance for the songs in a phenomenon in the modern world and thereby testing a new, but certainly not definitive, point of departure for understanding the enigmatic Caryāgiti, the Songs of (Yogic) Practice.

\section{References}

Dasgupta, Sh. 1969 (1946). Obscure Religious Cults: As a Background of Bengali Literature. Calcutta: K. L. Mukhopadhyay.

Dimock, Edward C. 1989. The Place of the Hidden Moon: Erotic Mysticism in the Vaisnava-Sahajiya Cult of Bengal. Chicago: The University of Chicago Press.

Kværne, Per. 1977. An Anthology of Buddhist Tantric Songs: A Study of the Caryāgitti. Oslo: Universitetsforlaget. $\left(2^{\text {nd }}\right.$ edition, Songs of the Mystic Path 1986, Bangkok: White Orchid Press; $3^{\text {rd }}$ edition 20I0, Bangkok: Orchid Press.)

Levy, Silvano. 20I 5. Decoding Magritte. Bristol: Sansom \& Co.

Mahaswati Devi. 2002. The Book of the Hunter. Kolkata: Seagull Books.

Moudud, Hasna Jasimuddin. I992. A Thousand Year Old Bengali Mystic Poetry, Dhaka: University Press.

Openshaw, Jeanne. 2002. Seeking Bauls of Bengal. Cambridge: Cambridge University Press.

Shastri, Haraprasad (ed.). 2006. Hajar Bacharer Purano Bangala Bhasay Bauddhagan o Doha (in Bengali). Kolkata: Bangiya Sahitya Parishad.

Snellgrove, David. 1987. Indo-Tibetan Buddhism and their Tibetan Successors. Bangkok: Orchid Press.

Spies, Werner \& Rewald, Sabine (eds.). 2005. Max Ernst: A Retrospective. New York: Metropolitan Museum of Art. 